\title{
A Deeper Look at the Proportionality-Turnout Nexus
}

\author{
Peter Selb \\ University of Konstanz, Germany
}

Evidence that turnout is higher under proportional representation (PR) than in majoritarian elections is overwhelming. Yet previous research has largely failed to explain why. One line of argument maintains that higher turnout under PR is a by-product of larger party systems. However, a larger number of parties has been demonstrated to depress turnout. Alternatively, it is argued that majoritarian electoral systems tend to produce safe seats and that voters have little incentive to turn out there. Thus, uneven turnout over electoral districts due to variable intensities of local competition is made responsible for the lower overall turnout. Empirical evidence on this conjecture is scant. This article scrutinizes the relationship between electoral rules, competition, and turnout with district-level data from 31 national elections. Results from a heteroscedastic model indicate that lower net turnout in majoritarian systems is indeed a consequence of uneven turnout over districts due to variable levels of local competitiveness.

Keywords: turnout; electoral systems; electoral competition; proportionality; electoral districts

$\mathrm{T}$ There is wide agreement among scholars that the proportionality of electoral systems (i.e., the correspondence they tend to produce between party vote shares in the electorate and party seat shares in the elected bodies) is positively associated with voter participation. For example, Blais and Dobrzynsky (1998), Franklin (2002), Jackman (1987), and Jackman and Miller (1995) report significant effects of different proportionality indices in their cross-national studies of voter turnout. Focusing on electoral formulae

Author's Note: An earlier version of this article was presented at the World Meeting of the Public Choice Society in Amsterdam, April 2007. The author would like to thank the workshop participants, in particular Bernard Grofman, Daniel Bochsler, Thomas Gschwend, Hanspeter Kriesi, and several anonymous reviewers for their valuable comments. 
as one factor determining the degree of proportionality, Blais and Carty (1990), Blais and Dobrzynsky (1998), Crewe (1981), Norris (2004), and Siaroff and Merer (2002) demonstrate that voter turnout is higher in proportional list systems than in majoritarian winner-takes-all systems. Powell (1980, 1986), Jackman (1987), and Jackman and Miller (1995) combine the electoral formula with district magnitude as another potential source of proportionality (Rae, 1971; Taagepera \& Shugart, 1989) and find that singlemember district (SMD) plurality systems generate lower turnout rates than multimember proportional representation (PR) systems with average district magnitudes between three to five seats, which in turn display lower turnout figures than PR countries with larger districts or a single national district. In a longitudinal perspective, Gosnell (1930) reports that turnout in Switzerland rose by $20 \%$ after it changed its electoral system from plurality to PR in 1919. New Zealand, which changed its electoral formula from plurality to mixed-member proportional, experienced a reversal in a longterm downward trend in voter turnout in 1996 (Karp \& Banducci, 1999), although this reversal has turned out to be rather short lived in nature (Vowles, 2002). At the local level, Bowler, Brockington, and Donovan (2001) demonstrate that recent transitions from plurality to cumulative vote systems in the United States have fostered a 5 percentage point growth in turnout. Finally, Geys (2006a) finds in his meta-analysis of 14 studies, including 71 estimates of the relationship between the proportionality of the electoral system and turnout, that $70 \%$ of the estimates succeed in actually demonstrating a positive effect of proportionality on turnout.

Although the evidence is thus relatively unambiguous, disagreement emerges on its explanation (for a recent review, see Blais, 2006; Blais \& Aarts, 2006). It has frequently been theorized and observed that majoritarian electoral systems tend to lead to two-party sytems in which the two competitors converge to the ideological center, whereas PR elections facilitate the emergence of multiple, ideologically distinct parties (see, e.g., Cox, 1997). Hence, some authors have blamed limited choice sets, ideological indistinguishability between the alternatives, and resulting weak partisan ties as the causes of low turnout under majoritarian rule. However, many studies have demonstrated that larger party systems in fact depress turnout (see, e.g., Blais \& Carty, 1990; Blais \& Dobrzynsky, 1998; Brockington, 2004; Jackman, 1987; Jackman \& Miller, 1995). In line with these findings, Powell (2000) has argued that elections in larger party systems often result in coalition governments where negotiation among elites, rather than the election outcome itself, determines the executive responsibility. Thus, we are, in Blais and Aarts' (2006) words, "left with the conclusion that if PR 
fosters turnout, it is not because there are more parties; in fact, it could be despite the presence of more parties" (p. 190).

On the other hand, it has been argued that majoritarian systems produce safe seats in districts where the relative strength of parties is heavily biased. Thus, parties have little incentive to mobilize, and voters have little incentive to turn out in such districts. In contrast, PR systems are especially designed to ensure that every vote counts, so that local contests should always be competitive (see, e.g., Blais \& Carty, 1990; Cox, 1999; Franklin, 2004; Powell, 1980). Lower national-level turnout in disproportionate electoral systems would therefore be a consequence of uneven turnout over districts, which in turn would be a consequence of varying intensities of local-level competition. Although this conjecture is highly plausible, empirical evidence is scant. To be sure, some international comparative studies use national margins of victory to model the effect of electoral competitiveness on turnout (Blais \& Dobrzynsky, 1998; Franklin, 2002). National and district margins are quite another cup of tea, though. Only Franklin (2004) uses mean margins of victory across districts in majoritarian systems (coded 0 for PR systems) and finds that this measure displaces the effect of the PR system variable in a multivariate analysis of national turnout. Although this result lends some tentative support for the above argument, most of the empirical implications of a theoretical account that is motivated by district-level rationale inevitably go undetected in nationallevel studies. District-level studies of the competition-turnout link, on the other hand, have exclusively focused on majoritarian electoral systems such as Canada, the United Kingdom, or the United States (for an overview of 29 studies, see Blais, 2000). Although the majority of these studies indeed find that turnout increases when district-level margins of victory wither in first-past-the-post races, there is still no systematic comparative empirical evidence on the role of electoral competition in the nexus of proportionality and turnout to date.

The intention of this article is to fill this gap. In the following section, I lay out the theoretical argument in detail. In doing so, I draw heavily on Cox's (1999) reflections on the classical Downsian model of voter turnout (Downs, 1957). Subsequently, I describe how I have operationalized the relevant constructs by means of district-level data from the Comparative Study of Electoral Systems (CSES), including observations on 3,194 constituencies in 31 national elections in 20 countries. The measurement of the central explanatory variable poses some particular challenges, because common measures of the competitiveness in two-party plurality elections do not easily generalize to elections held under PR and in multiparty systems. 
Then, I set up a mixed heteroscedastic model of turnout that accounts for both the mean-altering and variance-altering effects of electoral rules (recall that the primary implication of the above conjecture is that turnout should be more variable over districts in disproportionate electoral systems). Finally, I present statistical results and conclude.

\section{Electoral Rules, Electoral Competition, and Turnout}

\section{The Pivotal Voter Model}

According to the classical decision-theoretic model of turnout (Downs, 1957), a citizen will vote only if the benefits gained through his or her favored candidate or party winning the election, weighted by the probability of his or her vote being decisive, exceed the costs of voting. Because the probability that a single vote will be decisive is almost always near zero in mass electorates (see, e.g., Mulligan \& Hunter, 2003) and the benefits of voting are collective goods rather than private goods (e.g., Aldrich, 1993), the model predicts that no one should vote unless the costs of participation are negligible or voters vastly overestimate the probability of a pivotal vote. ${ }^{1}$

Although this model is obviously ill-suited to explain overall turnout levels in mass elections, it performs much better in predicting differences in turnout across contexts that vary with respect to costs, benefits, and probabilities of decisive votes (for an overview, see Aldrich, 1993; Dhillon \& Peralta, 2002; Dowding, 2005; Geys, 2006b; Grofman, 1993). Indeed, many studies find that turnout increases as expected or actual margins of victory decrease (see Blais, 2000; Matsusaka \& Palda, 1993). From the perspective of the instrumental voter characterized in the above model, however, close elections normally differ from foregone contests only in that they increase the probability of the individual's vote being decisive from infinitesimal to incredibly low. It is therefore difficult to imagine that voters notice, let alone react to, such small shifts.

\section{The Pivotal Elites Model}

Some authors argue that parties increase their mobilization efforts in the face of a close election and that voters respond to these efforts rather than to the objective conditions (see Cox \& Munger, 1989; Karp, Banducci, \& Bowler, 2008; Rosenstone \& Hansen, 1993; Shachar \& Nalebuff, 1999). The 
pivotal voter model sketched above then becomes a "strategic politicians" (Aldrich, 1993), "pivotal leader" (Shachar \& Nalebuff, 1999), or "pivotal elites model" (Cox, 1999; Cox \& Munger, 1989), according to which parties mobilize their potential voters if the benefits gained through winning parliamentary seats, weighted by the probability that the mobilization effort will be decisive, exceed their mobilization costs. The parties' mobilization efforts, in turn, decrease the voters' costs of participating, for example, in providing information on the parties' platforms and candidates or simply in organizing volunteers that drive prospective voters to the polls. Moreover, by activating social networks, the parties may impose social pressure on those who do not participate, thus increasing the costs of abstention (Rosenstone \& Hansen, 1993). Finally, the parties' mobilization efforts may provide potential voters with a signal of how close the race will be and hence on the probability that their own vote will be decisive. We would therefore generally expect turnout to be higher in close races (Hypothesis 1).

\section{Electoral Rules and Electoral Competition}

But how does the electoral system affect the parties' incentives to mobilize their electorates? The pivotal elites model suggests that parties will increase their mobilization efforts if these efforts translate more favorably into votes, if additional votes translate more favorably into legislative seats, and if the benefits of legislative seats are high (Cox, 1999). Electoral rules, in turn, indirectly affect competition in that they govern the translation of votes into seats. For expository purposes, imagine just two electoral districts: one single-member plurality district and one four-member PR district that applies the D'Hondt method of seat allocation. ${ }^{2}$ In both districts, only two parties, A and B, are competing, where $\mathrm{A}$ is expected to receive a vote share of approximately .70 and B is expected to gain about .30 of the votes. Clearly, in the SMD, the mobilization effort will only be worthwhile for party $B$ if it can be reasonably expected to result in not less than an additional .20 share of the votes, because the minimum required plurality in an SMD with two parties competing is .50 , and $.50-.30=.20$. Given that the electorate of $\mathrm{A}$ is at least partially composed of strong partisans, this may well be a hopeless venture. Consequentially, both parties A and B will probably refrain from wasting their scarce resources on costly campaigns, and many potential voters of $A$ and $B$ that would respond primarily to the actcontingent incentives by the parties will probably abstain. Moreover, potential voters of party B may stay at home to a disproportionately higher extent to avoid wasting their votes. 
In the PR district, on the other hand, the race for the marginal seat will be considerably closer. Given the expected vote shares under D'Hondt, party A will get the first (because $.70>.30$ ) and second seat (because $.70 / 2>.30$ ), party B will get the third (because $.30>.70 / 3$ ) and party A will get the fourth and final seat (because $.70 / 3>.30 / 2)$. However, party B will need just another .10 share of the votes plus to dispute party A's final seat, because $.60 / 3=(.30+$ .10)/2. Hence, our hypothetical four-member PR district may be considered twice as competitive as the SMD by design. Note that the vote shares that party B needs to win the seat in the hypothetical SMD (.50) and to win a second seat in the PR district (.40) may both be written as a simple function of the seat under consideration $s$ and the district magnitude $S: s \times[1 /(S+1)]$, which yields $1 \times[1 /(1+1)]=.50$ in the former and $2 \times[1 /(4+1)]=.40$ in the latter case. The expression in box brackets is also known as the "threshold of exclusion" (i.e., the maximum vote share with which it is possible not to win a seat; Gallagher, 1992; Lijphart \& Gibberd, 1977; Loosemore \& Hanby, 1971; Rae, Hanby, \& Loosemore, 1971). ${ }^{3}$ Thus, the threshold of exclusion provides the lower bound on the competitiveness of a given district: In an SMD, the exclusion threshold reaches its theoretical maximum of .50. Therefore, races can range over the full variety from close to foregone. In multimember PR districts, the threshold decreases primarily as a function of the district magnitude 4 and thus defines the maximum level of hopelessness a party may be faced with in an election. Therefore, we would expect party mobilization efforts and voter turnout to be more variable both over space and time, the higher the exclusion threshold gets (Hypothesis 2). Empirical evidence that higher thresholds produce higher turnout variance is scant (see Cox, 1999). Only Cox, Rosenbluth, and Thies (1998) demonstrate that the variance in closeness and turnout differed systematically between three-, four-, and five-member districts in Japanese parliamentary elections before the electoral system was changed from multimember district plurality to a parallel mixed system in 1994.

But how does turnout variability over districts and within districts over time relate to national turnout levels? The pivotal elites model suggests that parties will increase their mobilization efforts and hence turnout if the benefits of legislative seats are high. Because there is no a priori reason to assume that seats are more beneficial in single-member plurality than in multimember PR districts, we would not expect any differences in turnout levels between SMD and PR districts, keeping competitiveness constant (Hypothesis 3). If true, increasing turnout variability over districts inevitably implies lower net turnout at the national level. Therefore, turnout should be lower on average, the higher the threshold of exclusion gets (Hypothesis 4). 
So far, we have assumed that seats are exclusively allocated in the primary electoral districts. ${ }^{5}$ Many electoral systems include more than one layer in which the upper tiers are used either to compensate for the eventual disproportionalities in the vote-seat translation emanating from the primary districts (e.g., Germany), or to independently distribute additional regional or national seats, often according to a different electoral formula (e.g., post1994 Japan). Particularly in the former case, the introduction of a higher tier will presumably blur the competition-turnout link at the level of the primary electoral districts, as even parties that do not have any chance of winning a (or another) seat in a primary district will nevertheless have incentives to mobilize their electorates to receive more compensational seats at the upper tier(s). Therefore, we would expect that supradistrict corrections will produce higher overall turnout levels, weaker effects of primary district competitiveness on turnout, and lower magnitudes of cross-district variability in turnout (Hypotheses 5, 6, and 7).

\section{Data}

This analysis of turnout is based on data from the CSES. Established in 1994, the CSES currently includes 70 national parliamentary and presidential elections in 44 countries. In addition to election survey data, the CSES also includes contextual information at the national and district levels. It is unfortunate that not all the national collaborators have provided all the district data needed for the present analysis. Moreover, because the primary focus of the CSES is comparative survey-based research on voting behavior, data are only available for those electoral districts from which respondents were sampled and interviewed. ${ }^{6}$ This leaves us with 3,194 electoral districts observed in 31 national elections in 20 countries. See Table 1 for an overview of the countries and elections included in this study.

\section{Turnout}

The dependent variable of this analysis is, of course, electoral turnout at the district level (i.e., the proportion of actual voters among eligible citizens in an electoral district). Table 1 gives some descriptive information on turnout in the districts included in this study. Most notably, national turnout rates as reported in column 3 and the variabilities of turnout over electoral districts in column 5 are closely intertwined. Their correlation of -.73 gives strong support to our reasoning that low turnout in national elections is largely 
Table 1

Votor Turnout in 31 National Parliamentary Elections, 1996-2005

\begin{tabular}{|c|c|c|c|c|c|}
\hline Country & $\begin{array}{l}\text { Election } \\
\text { Year }\end{array}$ & $\begin{array}{r}\text { National } \\
\text { Turnout }\end{array}$ & $\begin{array}{c}M \text { District-Level } \\
\text { Turnoul }\end{array}$ & $\begin{array}{c}S D \text { District-Level } \\
\text { Turnout }\end{array}$ & $\begin{array}{l}\text { Number of } \\
\text { Districts }\end{array}$ \\
\hline Australia ${ }^{a}$ & 1996 & .958 & .959 & .012 & 134 \\
\hline Australia $^{a}$ & 2004 & .948 & .944 & .012 & 127 \\
\hline Belgium $^{a, h}$ & 1999 & .905 & .912 & .020 & 19 \\
\hline Canada & 1997 & .562 & .669 & .063 & 237 \\
\hline Canada & 2004 & .609 & .608 & .055 & 297 \\
\hline Denmark $^{h}$ & 1998 & .831 & .864 & .010 & 7 \\
\hline Finland & 2003 & .697 & .645 & .022 & 11 \\
\hline Germany $^{b}$ & 1998 & .791 & .821 & .028 & 317 \\
\hline Germany $^{\mathrm{h}}$ & 2002 & .822 & .789 & .040 & 504 \\
\hline Hungary $^{b}$ & 1998 & .599 & .575 & .060 & 70 \\
\hline Iceland $^{b}$ & 2003 & .877 & .879 & .015 & 6 \\
\hline Ireland & 2002 & .626 & .615 & .063 & 19 \\
\hline Japan & 1996 & .598 & .597 & .062 & 117 \\
\hline Mexico & 1997 & .544 & .553 & .104 & 96 \\
\hline Mexico & 2003 & .417 & .405 & .080 & 109 \\
\hline New Zealand ${ }^{h}$ & 1996 & .830 & .856 & .039 & 60 \\
\hline New Zealand ${ }^{h}$ & 2002 & .770 & .772 & .044 & 58 \\
\hline Norway $^{h}$ & 1997 & .768 & .703 & .037 & 10 \\
\hline Norway ${ }^{b}$ & 2001 & .755 & .752 & .016 & 13 \\
\hline Poland & 2001 & .463 & .457 & .028 & 26 \\
\hline Portugal & 2002 & 615 & .607 & .043 & 17 \\
\hline Portugal & 2005 & .643 & .635 & .039 & 17 \\
\hline Romania $^{b}$ & 1996 & .782 & .705 & .048 & 39 \\
\hline Spain & 1996 & .806 & .775 & .043 & 44 \\
\hline Spain & 2000 & .773 & .712 & .053 & 44 \\
\hline Spain & 2004 & .757 & .776 & .029 & 31 \\
\hline Sweden ${ }^{b}$ & 1998 & .814 & .806 & .016 & 29 \\
\hline Switzerland & 1999 & .434 & .495 & .063 & 11 \\
\hline Switzerland & 2003 & .454 & .469 & .063 & 17 \\
\hline United Kingdom & 1997 & .615 & .710 & .055 & 206 \\
\hline United Kingdom & 2005 & .594 & .618 & .063 & 502 \\
\hline Total & & .699 & .707 & .043 & 3,194 \\
\hline
\end{tabular}

a. Systems that use compulsory voting.

b. Systems that use supradistrict corrections.

a consequence of uneven turnout over electoral districts. ${ }^{7}$ Also in accordance with our theoretical expectations, classical PR systems such as that in Denmark, Finland, Iceland, Norway, and Sweden exhibit above-average national turnout rates and relatively low levels of interdistrict volatility. In contrast, the prototypical SMD systems of Canada and the United Kingdom 
display below-average turnout rates and clearly higher standard deviations of turnout than the former. To determine whether or not these observations can be attributed to distinct patterns and effects of electoral competition will be the primary task of the remainder of this article.

\section{Thresholds of Exclusion}

The threshold of exclusion provides the lower bound on the competitiveness of a given district and therefore sets the causal mechanism in motion that presumably accounts for the proportionality-turnout puzzle. As already mentioned, the threshold of exclusion indicates the maximum vote share with which it is possible not to win a seat. In a single-member plurality district, this is, of course, $50 \%$ of the votes, or $1 /\left(S_{i}+1\right)$, in which $S$ is the number of seats (here, 1) to be filled in district $i$. Canada and the United Kingdom are the only countries included in our sample that exclusively vote their members of parliament by SMD. Australia's Alternative Vote system also features a threshold of exclusion of .50. However, the two mixed-member proportional systems, Germany and New Zealand, and the so-called supermixed systems as practiced in Hungary allocate their constituency-level seats by SMD elections, too, although the resulting voteseat distortions are then mitigated via supradistrict corrections. ${ }^{8}$ With PR districts, the threshold of exclusion depends on the method of seat allocation, the district magnitude, eventual legal thresholds and, contingent on the electoral formula used, also on the number of candidates or parties competing in a respective district. The threshold of exclusion in PR countries that vote by the D'Hondt method of seat allocation, such as Belgium, Finland, Poland, Portugal, Spain, and Switzerland is also $1 /\left(S_{i}+1\right)$. The same applies to the Single Transferable Vote elections in Ireland. ${ }^{9}$ For the Modified Sainte Laguë method as practiced in Denmark, Norway, and Sweden, it is $1 /\left(2 S_{i}-P_{i}+2.4\right)$; that is, the number of competing parties $P_{i}$ has to be taken into account. When $P_{i}-1 \geq S_{i}$, the threshold of exclusion is $1 /\left(S_{i}+1\right)$ for all the methods (see Gallagher, 1992).

Some countries in the sample impose legal thresholds at the constituency level (i.e., a fixed percentage of the district vote that is required to be entitled to seats). These include Iceland $(6 \%)$, Norway (4\%), Poland $(5 \%)$, Romania (3\%), and Spain (3\%). ${ }^{10}$ If the legal thresholds exceed the effective thresholds, the effective thresholds will be replaced by these legal thresholds. Figure 1 presents a scatterplot of district-level turnout deviations from the national election averages over varying thresholds of exclusion. ${ }^{11}$ It is obvious that turnout indeed gets much more variable the higher the exclusion thresholds are. 
Figure 1

Deviations From Mean District-Level Turnout by Thresholds of Exclusion in 31 National Parliamentary Elections

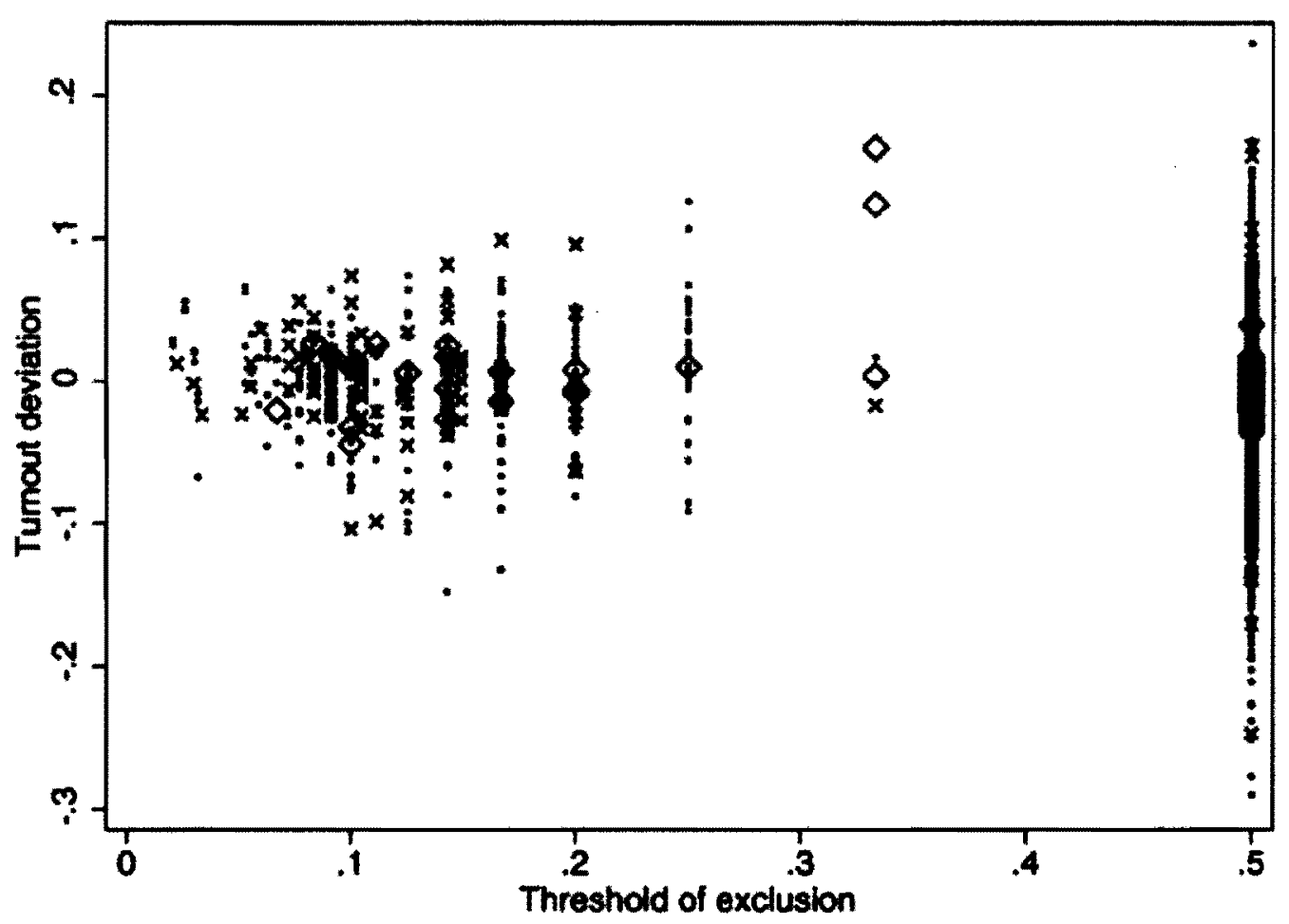

Note: $N=3,194$ clectoral districts; dots indicate electoral systems without supradistrict corrections, $x$ s indicate systems with supradistrict corrections, and diamonds represent systems with compulsory voting.

\section{Supradistrict Corrections}

Figure 1 also suggests that turnout tends to be less responsive to varying thresholds of exclusion in the primary districts when supradistrict corrections are applied. This observation corroborates our expectation that electoral systems that provide compensational mechanisms to mitigate the disproportionalities potentially emanating from the primary electoral districts will attenuate the interplay between electoral rules, competitiveness, and turnout. Supradistrict corrections is an indicator variable that takes on a value of 1 if there is some transfer of votes from the primary districts to an upper tier; otherwise 0 . Countries with supradistrict corrections include Belgium, Denmark, Germany, Hungary, Iceland, New Zealand, Norway, 
Romania, and Sweden (see Table 1). Supradistrict corrections are used as a stratification variable in the subsequent analysis.

\section{District Margins}

Varying local competitiveness is the immediate factor being made responsible for the observed proportionality-turnout nexus. In singlemember plurality districts, the competitiveness of the race is frequently measured by the percentage margin between the winner and the runner-up candidate or party. This operationalization has been criticized for various reasons (see, e.g., Cox, 1988; Elkins, 1974). Most important, it has been objected that actual election results may not accurately reflect pre-election expectations. However, because ex ante information such as forecasts based on pre-election polls are usually not available for all the districts of a given electoral system, there is virtually no alternative to using ex post measures, and the same is done in the present study. Following Cox (1988), we assume that pre-election expectations are correct on average. A major problem is, however, that the margin between the winner and the runner-up in plurality elections has no self-evident counterpart in multimember PR districts. A simple generalization of the vote margin in SMD would be to exclusively consider the contest for the final seat. This idea has already been used implicitly in the empirical exposition of the theoretical model. An elaboration of what this exactly means in the PR setting is also best illustrated with an empirical example or, because the calculation of the district margin so defined varies by the electoral formula used, by two examples. Table 2 shows how votes are transformed into seats in a hypothetical five-member PR district according to the D'Hondt and Modified Sainte Laguë highest average methods.

Both methods successively divide the votes shares for each party by a series of divisors: ${ }^{12} 1,2,3, \ldots$ in the case of D'Hondt and $1.4,3,5, \ldots$ in the case of Modified Sainte-Laguë. Seats are allocated one at a time to the party that achieves the highest fraction. If a party receives a seat, the subsequent fraction is considered. In the D'Hondt example, party A gets the first seat (with a vote share of .53 ), party B the second (with .30), party A the third and the forth (with .27 and .18, respectively), and party $\mathrm{C}$ the fifth seat (with .17). The race for the marginal seat is therefore fought out between parties $\mathrm{C}$ and $B$, because $B$ is, with a fraction of .15, the runner-up for the fifth seat. The district-level margin would then be calculated as $2 \times(.17-.15)=.04$, where 2 is the divisor that produced the respective fraction of .15 for party B. In other words, B would have needed another proportion of .04 of the votes 
Table 2

Distribution of Seats by Two Proportional Representation

Electoral Formulae in a Hypothetical District

With Five Seats, Three Parties Competing

\begin{tabular}{lclll}
\hline & Divisor & Party A & Party B & Party C \\
\hline D'Hondt & 1 & $.53(1)$. & $.30(2)$. & $.17(5)$. \\
& 2 & $.27(3)$. & .15 & .08 \\
& 3 & $.18(4)$. & & \\
Moditied Sainte-Laguë & 4 & .13 & & $.12(4)$. \\
& 1.4 & $.38(1)$. & $.21(2)$. & .06 \\
& 3 & $.18(3)$. & .10 & \\
& 5 & $.11(5)$. & & \\
\hline
\end{tabular}

Note: Ranks in parentheses indicate seats won.

to challenge party $\mathrm{C}$ for the final seat, all other things being equal. According to the Modified Sainte-Laguë method, the race for the marginal seat would be fought out between party $\mathrm{A}$ and $\mathrm{B}$, and the district margin would be $3 \times(.11-.10)=.03$. Figure 2 plots the district margins calculated in this way over the thresholds of exclusion. It is easily seen that district margins are indeed much more variable in high-threshold districts and that the exclusion threshold determines the maximum possible district margin. ${ }^{13}$

\section{Compulsory Voting}

According to Figure 2, compulsory voting seems to more or less fully counterbalance the effect of electoral system features on turnout variability. Turnout deviations are miniscule in the two countries that use the compulsory vote (Australia and Belgium), irrespective of the exclusion thresholds of the primary districts. The two outliers (the diamonds at a threshold of exclusion of slightly over .30) pertain to a single electoral district: Schaffhausen in Switzerland, which regulary features above-average turnout rates, because it is the only Swiss district where voting is compulsory. As interesting as these observations may be, there seems to be nothing left to be learned from any further inclusion of districts with compulsory voting in the subsequent analysis besides the fact that they generate very high turnout levels and very low levels of turnout variance. Therefore, Australia, Belgium, and the Swiss district of Schaffhausen will be excluded from the analysis. 
Figure 2

District Margins by Thresholds of Exclusion in 31 National Parliamentary Elections

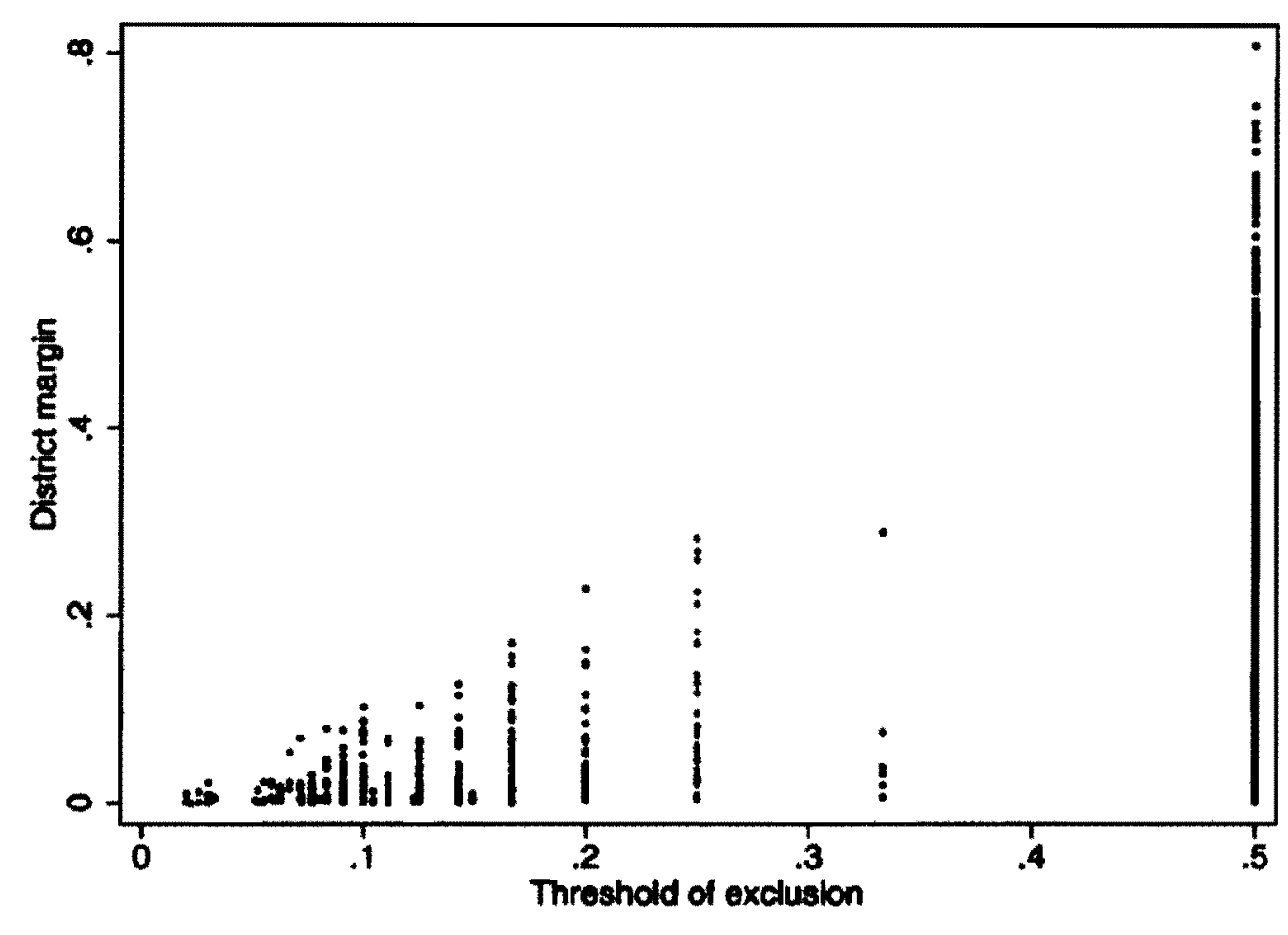

\section{An Empirical Model of District-Level Turnout}

In this section, I set up an empirical model of district-level turnout that accounts for both the mean-altering and variance-altering effects of electoral rules. In doing so, some additional complications have to be taken care of. First, turnout among potential eligibles is an outcome that is theoretically bounded between 0 and 1 . Linear models may yield out-of-bounds predictions in this case. The logit transform of turnout is therefore used to rid the bounds. ${ }^{14}$ Second, many factors external to the operating of the parliamentary electoral system may potentially cause overall turnout levels to vary from election to election and from country to country. For this very reason, deviations from the national election averages have been used in Figure 1 to illustrate the variance-altering effect of district thresholds. In the empirical model, I account for varying turnout levels between national elections 
by including random intercepts for the elections under investigation (see, e.g., Snijders \& Bosker, 1999). Having said this, the model of mean turnout (or the location submodel) takes the form:

$$
\ln \left(\frac{\text { Turnout }_{i j}}{1-\text { Turnout }_{i j}}\right)=\beta_{0}+\beta_{1} \text { Threshold }_{i j}+\mu_{j}+\varepsilon_{i j}
$$

where $\mu_{j}$ is an election-specific error term for which we assume a normal distribution with mean 0 and $\sigma_{\mu}^{2}$, and $\varepsilon_{i j}$ is a district-specific error term for which the usual regression assumptions apply. $\beta_{0}$ and $\beta_{1}$ are the parameters to estimate. According to the numerous previous findings cited above, we would expect a negative $\beta_{1}$ coefficient, which means that district-level turnout will be lower on average if the threshold of exclusion is higher (Hypothesis 4).

Because turnout is also hypothesized to be more variable in high-threshold districts, the residuals $\varepsilon_{i j}$ can be expected to be heteroscedastic. Therefore, $\varepsilon_{i j}$ is modeled as a function of the district's exclusion threshold (the dispersion submodel): ${ }^{15}$

$$
\ln \left(\varepsilon_{i j}^{2}\right)=\gamma_{0}+\gamma_{l} \text { Threshold }_{i j}+v_{i j}
$$

where the $\gamma \mathrm{s}$ are the parameters to estimate and $v_{i j}$ is a Gaussian error term. If thresholds raised turnout variance, we would expect a positive $\gamma_{1}$ estimate (Hypothesis 2). This model is a slightly modified random intercept version of Harvey's (1976) multiplicative heteroscedastic regression, and it allows us to simultaneously estimate the mean-altering and variance-altering effects of electoral rules on turnout. In a second step, the district margins is included in the location submodel:

$$
\ln \left(\frac{\text { Turnout }_{i j}}{1-\text { Turnout }_{i j}}\right)=\beta_{0}+\beta_{1} \text { Threshold }_{i j}+\beta_{2} \text { Margin }_{i j}+\mu_{j}+\varepsilon_{i j}
$$

If lower district margins produced higher levels of mobilization and, hence, turnout, we would expect a negative estimate of $\beta_{2}$ (Hypothesis 1). Furthermore, if uneven intensities of competition were the primary cause of higher turnout variability and hence lower average turnout in higher threshold districts, we would expect the estimates of $\beta_{1}$ and $\gamma_{1}$ to be considerably smaller in Model 2 as compared to Model 1 (Hypothesis 3). Models 1 and 2 are separately estimated for systems with and without supradistrict corrections. In systems with supradistrict corrections, we expect turnout to be 
generally higher ( $\beta_{0}$, Hypothesis 5$)$. At the same time, it has been hypothesized that supradistrict corrections mitigate the interplay between electoral rules, competitiveness, and turnout. Therefore, we would expect generally less turnout variance $\left(\gamma_{0}\right)$, irrespective of the threshold of a district (Hypothesis 7) and a smaller effect of the district margins $\left(\beta_{2}\right)$ on turnout in electoral systems that provide supradistrict corrections (Hypothesis 6). Statistical results are presented in the subsequent section.

\section{Findings}

Table 3 presents the estimates from the two mixed heteroscedastic models of turnout, each stratified by electoral systems that use supradistrict corrections and those that do not. ${ }^{16}$ Considering first the systems without compensatory provisions, Model 1 gives strong evidence of both meanaltering and variance-altering effects of exclusion thresholds on turnout. The respective coefficients in the location and the dispersion submodels are highly significant, and they point in the expected direction: the higher the threshold of exclusion, the lower the average turnout in the districts (Hypothesis 4) and the higher the turnout variance over districts (Hypothesis 2). But is this really a consequence of uneven intensities of electoral competition? A comparison of Models 1 and 2 suggests that this is indeed the case, at least to some extent. District margins exert a highly significant influence on turnout: the lower the margin, the higher the turnout (Hypothesis 1). Moreover, as we introduce the district-level margins in the location submodel, the effects of the threshold of exclusion on both the levels and the variance of turnout diminish considerably. The same applies to the variance of the random intercepts, which is smaller in Model 2 , indicating that distinct average levels of competitiveness at least partially account for turnout differences between elections and countries. Finally, the likelihood ratio test strongly suggests that Model 2 is a closer reflection of the data than Model 1.

Would turnout still systematically differ over electoral systems, with levels of local competition being equal? As an attempt to answer this counterfactual question, Figure 3 uses the estimated parameters of Models 1 and 2 to present predicted turnout levels and their respective confidence intervals by the districts' thresholds of exlusion with varying margins (left panel) and with margins held constant at 0 (right panel; i.e., at the maximum possible level of competition). As we can see, a considerable degree of the initially observed differences in turnout means and variances between districts with 
Table 3

Estimates From the Mixed Heteroscedastic Models of the Logit of District-Level Turnout in 28 National Parliamentary Elections

\begin{tabular}{|c|c|c|c|c|}
\hline & Model 1 & $S E$ & Model 2 & $S E$ \\
\hline \multicolumn{5}{|c|}{ Systems without supradistrict corrections } \\
\hline \multicolumn{5}{|l|}{ Fixed part: Location submodel $(\beta \mathrm{s})$} \\
\hline Intercept & 0.789 & $.020^{*}$ & 0.827 & $.024^{*}$ \\
\hline Threshold of exclusion & -0.660 & $.044^{*}$ & -0.329 & $.053^{*}$ \\
\hline District margin & & & -0.531 & $.048^{*}$ \\
\hline \multicolumn{5}{|c|}{ Fixed part: Dispersion submodel $(\gamma)$} \\
\hline Intercept & -1.667 & $.069^{*}$ & -1.608 & $.068^{*}$ \\
\hline Threshold of exclusion & 0.954 & $.147^{*}$ & 0.629 & $.144^{*}$ \\
\hline \multicolumn{5}{|l|}{ Random part $\left(\sigma_{u}^{2}\right)$} \\
\hline Intercept variance & 0.208 & $.008^{*}$ & 0.155 & $.006^{*}$ \\
\hline Number of districts & 1,799 & & 1,799 & \\
\hline Number of elections & 17 & & 17 & \\
\hline Log likelihood & -363 & & -209 & \\
\hline LR Test (Model 1 is nested; $1 \mathrm{df}$ ) & & & $309^{*}$ & \\
\hline \multicolumn{5}{|l|}{ Systems with supradistrict corrections } \\
\hline \multicolumn{5}{|l|}{ Fixed part: Location submodel $(\beta \mathrm{s})$} \\
\hline Intercept & 1.419 & $.176^{*}$ & 1.423 & $.176^{*}$ \\
\hline Threshold of exclusion & -0.395 & .358 & -0.363 & .313 \\
\hline District margin & & & -0.171 & $.063^{*}$ \\
\hline \multicolumn{5}{|l|}{ Fixed part: Dispersion submodel $(\gamma)$} \\
\hline Intercept & -1.860 & $.095^{*}$ & -1.854 & $.095^{*}$ \\
\hline Threshold of exclusion & 0.705 & $.198^{*}$ & 0.685 & $.198^{*}$ \\
\hline \multicolumn{5}{|l|}{ Random part $\left(\sigma_{u}^{2}\right)$} \\
\hline Intercept variance & 0.218 & $.094^{*}$ & 0.221 & $.095^{*}$ \\
\hline Number of districts & 1,113 & & 1,113 & \\
\hline Number of elections & 11 & & 11 & \\
\hline Log likelihood & 80 & & 92 & \\
\hline LR Test (Model 1 is nested; $1 d f$ ) & & & $7^{*}$ & \\
\hline
\end{tabular}

$*_{p}<.01$, all the other coefficents not significant at $p<.10$.

higher and lower thresholds of exclusion disappears as soon as we control for the competitiveness. This observation strongly supports the theoretical model (Hypothesis 3).

Turning now to the electoral systems that provide supradistrict corrections to compensate for eventual disproportionalities in the vote-seat translations at the level of the primary electoral districts, the estimates of Model 1 suggest quite a different picture. The threshold of exclusion does not significantly depress electoral turnout any longer. At the same time, the overall variance of turnout $\left(\gamma_{0}\right)$ is lower and the effect of the exclusion threshold on the variance 
Figure 3

Predicted Turnout by Threshold of Exclusion: Observed

District Margins (Model 1: Left Panel) and District Margins

Held Constant at 0 (Model 2: Right Panel)
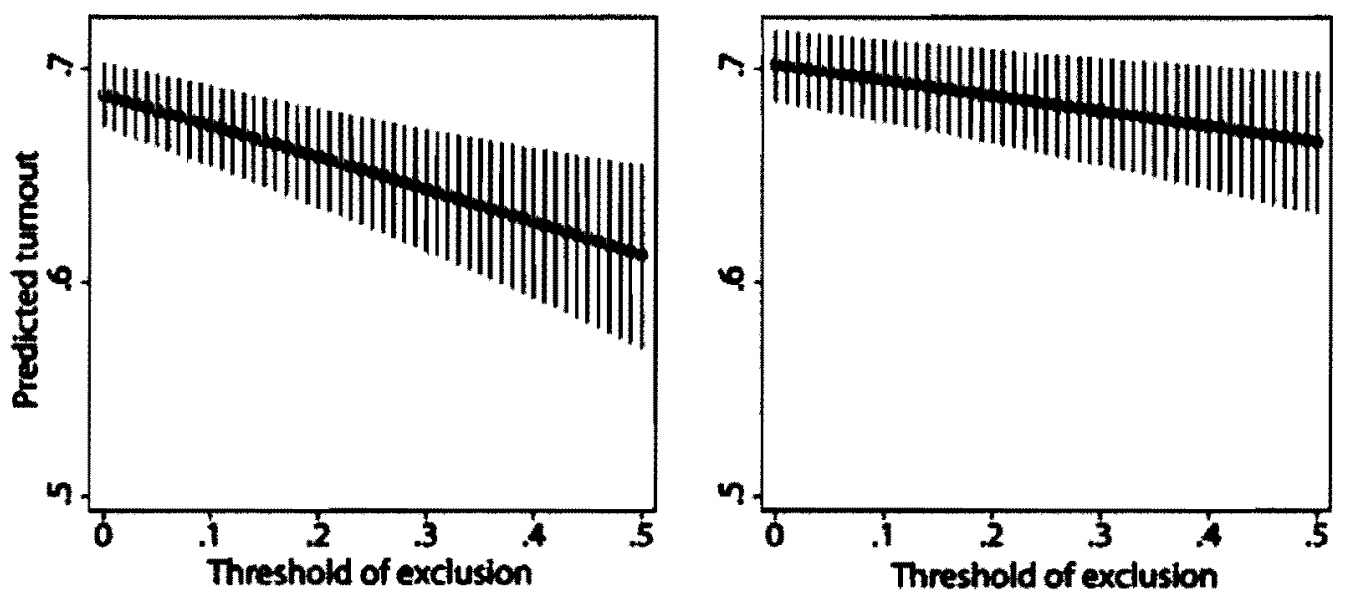

Note: Only districts from electoral systems without supradistrict corrections are considered. Bars represent $95 \%$ confidence intervals.

tends to be smaller than in districts without compensatory mechanisms (Hypothesis 7). Moreover, a comparison of the overall intercept $\beta_{0}$ of Model 1 in our two sample strata suggests that average turnout is notably higher in compensatory systems (Hypothesis 5). Thus, our results confirm that compensatory systems manage to overcome the drawbacks of disproportional, noncompensatory systems in terms of electoral competition and turnout. The inclusion of the district margins does not considerably change this picture. Obviously, lower district margins also increase turnout in corrective systems, but not to the same extent as in systems without compensational mechanisms (Hypothesis 6). In the same vein, the introduction of district margins in the location submodel does not considerably reduce the effect of exclusion thresholds on turnout variance. Thus, the role of primary district competitiveness in compensatory systems is negligible. Or in other words, systems with supradistrict corrections seem to ensure that elections are competitive everywhere.

\section{Discussion}

The empirical relationship between proportionality and turnout has long puzzled comparative electoral researchers. Conjectures that PR systems 
enhance turnout by facilitating the emergence of multiple and ideologically distinct parties have failed empirically. The alternative argument that majoritarian systems breed local competitions of varying intensities while PR elections guarantee more even levels of competitiveness has not been adequately scrutinized so far. In this article, I have set up a mixed heteroscedastic model of turnout using district-level data from 28 national parliamentary elections in 18 countries. The results strongly support the hypothesis that turnout differences between majoritarian and PR systems are indeed a consequence of more variable local patterns of competition in former.

Two general conclusions suggest themselves: First, comparative electoral research can profit considerably from disaggregating and taking the level of electoral districts into account. Many contextual models of voting behavior and party competition naturally operate at the level where votes are transformed into seats and not exclusively at the national level of electoral systems (for some excellent examples of comparative district-level research, see Cox, 1997; Monroe \& Rose, 2002). Second, most political scientists seek evidence of causal processes by solely measuring changes in the mean of a dependent variable of interest. This article examplified that some causal relationships imply changes in both the mean and the variance of a dependent variable. I therefore fully agree with Braumoeller's (2006) recent appeal to extend our understanding of causation as to include variancealtering types of effects.

This said, some qualifications are due. First, it has been argued that marginality affects turnout primarily via elite mobilization efforts. However, mobilization efforts have been inferred rather than observed in this study. What is needed to empirically discriminate between the pivotal voter and the pivotal elites model in the context of a comparative study of the proportionalityturnout nexus are district-level measures of party mobilization efforts (e.g., data on campaign spending, which are not readily available yet for a wide range of national elections under diverse electoral rules). For the same reason, this study has conceptualized electoral competition purely in interparty terms. However, intraparty competition may also be relevant to mobilization and turnout in preferential voting systems such as in Denmark, Finland, Ireland, or Poland. A potential remedy is on its way, though. Only recently, the Comparative Candidate Survey, a candidate-level survey program to investigate election campaigns and political representation in a comparative perspective, has been established with some 20 national election studies as founding members. However, it will surely take some time until the relevant data will be available for a satisfying number of countries. Finally, this study has exclusively focused on the role of local competition because this has 
demonstrably been the missing link in the proportionality-turnout puzzle. A more complete account of the interplay between electoral rules, electoral competition, and turnout would also consider the potential effect of national margins. Hypotheses on differential effects of national competition on turnout in proportional and majoritarian systems can easily be deduced from the decision-theoretical model of turnout (see Cox, 1999). In particular, the closeness of the national race should primarily affect elite mobilization efforts and hence turnout in low-threshold electoral districts, because voters and parties in hopeless SMDs would not be able to influence the national balance of power, whatever their mobilization efforts and propensities to turn out were. This conjecture probably presents the most fruitful avenue for future research.

\section{Notes}

1. Indeed, Blais (2000) gives empirical evidence that individuals massively overestimate the decisiveness of their vote.

2. According to the D'Hondt method of seat allocation, the vote shares for each party are successively divided by a series of divisors $1,2,3$, and so forth. Seats are allocated one at a time to the party that achieves the highest fraction. A more detailed description of alternative methods of seat allocation follows in the Data section.

3. By coincidence, the threshold of exclusion also equals the minimum vote share required to win a seat in our hypothetical example, which is $1 /(S-1+P)$, where $P$ is the number of parties competing. It is easily seen that both measures will be identical if $P=2$.

4. As will be seen later in the article, the threshold of exclusion also depends on potential legal thresholds, the method of seat allocation, and eventually, on the number of parties competing.

5. If a district cannot be partitioned into smaller districts within which votes are counted and seats allocated, it is called primary.

6. Many national election studies in single-member district (SMD) systems such as the United States draw samples of respondents from a sclection of clectoral districts to enhance multilevel analyses of voting behavior (see, e.g., Stoker \& Bowers, 2002). In these instances, we would lose relatively large numbers of electoral districts. In many PR systems, on the other hand, election surveys are based on a national random sample of voters. In these instances, we probably lose smaller electoral districts, because the selection probability of voters from small districts is naturally lower in a national random sample. However, there is no immediate reason why these types of selectivity should harm the results of the analysis in the present context.

7. Note that this correlation is not an artifact of the inclusion of the two compulsory voting systems. Excluding Australia and Belgium, the magnitude is still -.63.

8. In contrast, SMD and PR components operate independently of each other in parallel systems such as in Mexico and Japan. Their constituencies are therefore treated as pure SMD.

9. For Alternative Vote and Single Transferable Vote, the vote shares included in the CSES refer to first preferences only. For an overview of these peculiar electoral systems, see Bowler \& Grofman (2000).

10. A number of countries impose legal thresholds at the national level (e.g., Germany). However, it is difficult to imagine how these thresholds may be incorporated into our index of 
exclusion. The same applies to the Swedish regulations that require parties to either gain $4 \%$ of the national vote or $12 \%$ of the vote in any district.

11. As is obvious from Table 1, levels of turnout may differ from election to election and from country to country for reasons unrelated to the causal mechanism investigated here. For example, the exceptionally low turnout in Switzerland is frequently ascribed to the massive use of direct democracy, consociational government, and late female enfranchisement (see Franklin, 2004; Powell, 1980). Therefore, it seems reasonable to rid the noise from national diflerences in turnout levels for the moment.

12. Formally, the methods operate with the number of votes. However, the CSES provides party vote shares instead of totals. This does not principally change the computation of district margins. A more severe problem is that the CSES only includes information on a maximum of six parties (Module 1) and eight parties (Module 2). In districts with more than six (and eight, respec(ively) competitors, the data are therefore incomplete. I have excluded districts where information on more than $10 \%$ of the total vote share is missing. Otherwise, I have lumped the missing vote share into a residual category that is treated as it was a party when computing the district margin.

13. In preferential voting systems, marginality may also be conceptualized in terms of intraparty instead of interparty competition. Unfortunately, the CSES does not provide the relevant data to measure competition in intraparty terms.

14. Proportions are also susceptible to exhibit skew, multimodality, and heteroscedasticity, thus violating the normal regression assumptions. Sometimes a beta distribution is therefore assumed to model proportions (e.g., Paolino, 2001). The advantage of beta regression is not solely its distributional flexibility but also its straightforward implementation of variancealtering types of effects. However, an inspection of our dependent variable does not indicate any skew or multimodality after stratifying by supradistrict corrections. Moreover, the mean and dispersion parameters in beta regression place no restrictions on each other and are therefore ill suited for the sequential modeling strategy that is later proposed in this article.

15. The residuals are squared because, of course, the variance cannot be negative. The natural logarithm is used to stabilize the variance.

16. The parameters were estimated using GLLAMM, a Stata program to fit generalized linear latent and mixed models (see Skrondal \& Rabe-Hesketh, 2004). I used Gauss-Hermite quadrature to integrate out the random effects and the Newton-Raphson method to maximize the model's marginal likelihood.

\section{References}

Aldrich, J. H. (1993). Rational choice and turnout. American Journal of Political Research, 37 , 246-278.

Blais, A. (2000). To vote or not to vote: The merits and limits of rational choice theory. Pittsburgh, PA: University of Pittsburgh Press.

Blais, A. (2006). What affects voter turnout? Annual Review of Political Science, 9, 111-125. Blais, A., \& Aarts, K. (2006). Electoral systems and tumout. Acta Politica, 41, 180-196.

Blais, A., \& Carty, R. K. (1990). Does proportional representation foster turnout? European Journal of Political Research, 18, 167-181.

Blais, A., \& Dobrzynsky, A. (1998). Turnout in electoral democracies. European Journal of Political Research, 33, 239-261.

Bowler, S., Brockington, D., \& Donovan, T. (2001). Election systems and voter turnout: Experiments in the United States, Journal of Politics, 63, 902-915. 
Bowler, S., \& Grofman, B. (Eds.). (2000). Elections in Australia, Ireland, and Malta under the Single Transferable Vote: Reflections on an embedded institution. Ann Arbor: University of Michigan Press.

Braumoeller, B. F. (2006). Explaining variance or stuck in a moment we can't get out of. Political Analysis, 14, 268-290.

Brockington, D. (2004). The paradox of proportional representation: The effect of party systems and coalitions on individuals' clectoral participation. Political Studies, 52, 469-490.

Cox, G. W. (1988). Closeness and turnout: A methodological note. Joumal of Politics, 50, 768-775.

Cox, G. W. (1997). Making votes count. Strategic coordination in the world's electoral systems. Cambridge, UK: Cambridge University Press.

Cox, G. W. (1999). Electoral rules and the calculus of mobilization. Legislative Studies Quarterly, 24, 387-419.

Cox, G. W., \& Munger, M. C. (1989). Closeness, expenditures, and turnout in the 1982 U.S. House elections. American Political Science Review, 83, 217-231.

Cox, G. W., Rosenbluth, F., \& Thies, M. (1998). Mobilization, social networks and turnout: Evidence from Japan. World Politics, 50, 447-472.

Crewe, I. (1981). Electoral participation. In D. Butler, H. R. Penniman, \& A. Ranney (Eds.), Democracy at the polls. A comparative study of competitive national elections (pp. 216263). Washington, DC: American Enterprise Institute.

Dhillon, A., \& Peralta, S. (2002). Economic theories of voter turnout. Economic Journal, 112, F332-F352.

Dowding, K. (2005). Is it rational to vote? Five types of answer and a suggestion. The British Journal of Politics and International Relations, 7(3), 442-459.

Downs, A. (1957). An economic theory of democracy. New York: Harper \& Row.

Elkins, D. J. (1974). The measurement of party competition. American Political Science Review, 68, 682-700.

Franklin, M. N. (2002). The dynamics of electoral participation. In L. LeDuc, R. G. Niemi, \& P. Norris (Eds.), Comparing democracies 2: New challenges in the study of elections and voting (pp. 148-168). London: Sage.

Franklin, M. N. (2004). Voter turnout and the dynamics of electoral competition in established democracies since 1945. Oxford, UK: Cambridge University Press.

Gallagher, M. (1992). Comparing proportional representation electoral systems: Quntas, thresholds, paradoxes and majorities. British Journal of Political Science, 22, 469-496.

Geys, B. (2006a). Explaining voter turnout: A review of aggregate-level research. Electoral Studies, 25, 637-663.

Geys, B. (2006b). 'Rational' theories of voter turnout: A review. Political Studies Review, 4, $16-35$.

Gosnell, H. F. (1930). Why Europe votes. Chicago: University of Chicago Press.

Grofman, B. (1993). Is turnout the paradox that ate rational choice theory? In B. Grofman (Ed.), Information, participation and choice: An economic theory of democracy in perspective (pp. 93-103). Ann Arbor: University of Michigan Press.

Harvey, A. C. (1976). Estimating regression models with multiplicative heteroscedasticity. Econometrica, 44, 461-465.

Jackman, R. W. (1987). Political institutions and voter turnout in industrial democracies. American Political Science Review, 81, 405-421.

Jackman, R. W., \& Miller, R. A. (1995). Voter turnout in the indistrial democracies during the 1980s. Comparative Political Studies, 27, 467-492.

Karp, J. A., \& Banducci, S. (1999). The impact of proportional representation on turnout: Evidence from New Zealand, Australian Journal of Political Science, 34, 363-377. 
Karp, J. A., Banducci, S. A., \& Bowler, S. (2008). Getting out the vote: Party mobilization in a comparative perspective, British Journal of Political Science, 38, 91-112.

Lijphart, A., \& Gibberd, R. W. (1977). Thresholds and payoffs in list systems of proportional represcntation. European Journal of Political Research , 5, 219-244.

Loosemore, J., \& Hanby, V. J. (1971). The theoretical limits of maximum distortion: Some analytical expressions for electoral systems. British Journal of Political Research, 1, 467-477.

Matsusaka, J. G., \& Palda, F. (1993). The Downsian voter mects the ecological fallacy. Public Choice, 77, 855-878.

Monroe, B. L., \& Rose, A. G. (2002). Electoral systems and unimagined consequences: Partisan effects of districted proportional representation. American Journal of Political Research, 46, 67-89.

Mulligan, C. B., \& Hunter, C. G. (2003). The empirical frequency of a pivotal vote. Public Choice, 116, 31-54.

Norris, P. (2004). Electoral engineering: Voting rules and political behavior. Cambridge, UK: Cambridge University Press.

Paolino, P. (2001). Maximum likelihood estimation of models of beta-distributed dependent variables. Political Analysis, 9, 325-346.

Powell, G. B. (1980). Voting turnout in thirty democracies: Partisan, legal, and socio-economic influences. In R. Rose (Ed.), Electoral participation (pp. 5-34). London: Sage.

Powell, G. B. (1986). American voter turnout in comparative perspective. American Political Science Review, 80, 17-43.

Powell, G. B. (2000). Elections as instruments of democracy. Majoritarian and proportional visions. New Haven, CT: Yale University Press.

Rae, D. W. (1971). The political consequences of electoral laws. New Haven, CT: Yale University Press.

Rae, D. W., Hanby, V., \& Loosemore, J. (1971). Thresholds of representation and thresholds of exclusion: An analytical note on electoral systems. Comparative Political Studies, 3 , 479-488.

Rosenstone, S. J., \& Hansen, J. M. (1993). Mobilization, participation, and democracy in America. New York: Macmillan.

Shachar, R., \& Nalebuff, B. (1999). Follow the leader: Theory and evidence on political participation. American Economic Review, 89, 525-547.

Siaroff, A., \& Merer, J. W. A. (2002). Parliamentary election turnout in Europe since 1990. Political Studies, 50, 916-927.

Skrondal, A., \& Rabe-Hesketh, S. (2004). Generalized latent variable modeling: Multilevel, longitudinal and structural equation models. Boca Raton, FL: Chapman \& Hall.

Snijders, T., \& Bosker, R. (1999). Multilevel analysis. An introduction to basic and advanced multilevel modeling. London: Sage.

Stoker, L., \& Bowers, J. (2002). Designing multi-level studies: Sampling votcrs and electoral contexts. Electoral Studies, 21, 235-267.

Vowles, J. (2002). Offsetting the PR effect? Party mobilization and turnout decline in New Zealand, 1996-99. Party Politics, 8, 587-605.

Peter Selb is a junior professor of political methodology at the Department of Politics and Management, University of Konstanz, Germany. Research interests include political behavior and public opinion. Recent publications appear in Electoral Studies, European Journal of Political Research, European Political Science Review, Party Politics, Political Behavior, and Public Choice. 